\title{
Mandibular Premolars with Bifurcated Canals
}

\author{
Nisha Garg ${ }^{1}$ Garima Sahni ${ }^{1}$ \\ 1Department of Conservative Dentistry and Endodontics, Bhojia \\ Dental College and Hospital, Baddi, Himachal Pradesh, India \\ ${ }^{2}$ Rayat Bahra Dental College and Hospital, Mohali, Punjab, India
}

Ajay Chhabra ${ }^{2}$ Shabnam Negi ${ }^{1}$

Address for correspondence Nisha Garg, MDS, House No. 2347, Sec 23 C, Chandigarh 160023, India (e-mail: drnishagarhg1@gmail.com).

Dent J Adv Stud 2020;8:32-34

\author{
Abstract \\ Keywords \\ - mandibular 1st and \\ 2nd premolars \\ - anomalous root canal \\ anatomy \\ - missed canals
}

Each tooth in the permanent dentition presents with extensive variation in the anatomy of root, along with variation in the number of canals in individual roots. The existence of accessory canals should be considered in all teeth since failure to clean and fill them can have poor impact on prognosis. Thus, it is extremely important for a clinician to keep abreast with the complete assessment of the anatomy and morphology of root canal system for a favorable treatment outcome. Mandibular premolars often present with a variation in anatomy and, thus, considered as a perplexity to the endodontist. This article reports clinical cases of bifurcated canals in mandibular first premolars.

\section{Introduction}

Primary goal of root canal treatment is three-dimensional cleaning, shaping, and obturation of pulp space. According to Seltzer and Bender, despite adhering to the basic principles, failures can occur. Hoen and Pink reported that the teeth requiring retreatment showed an incidence of $42 \%$ of missed canals. ${ }^{1}$ Slowey showed that mandibular premolars are challenging to treat due to their anomalous anatomy, most commonly being bifurcation of main canal at a sharp angle, possibly resulting in missing of a canal thus known as "endodontist's enigma."2 The present article reports the endodontic treatment of bifurcated canals in mandibular premolars.

\section{Case Report 1}

A 29-year-old patient reported with pain in lower left back teeth region to the Department of Endodontics. Clinical examination revealed that caries with respect to mandibular left first and second premolar, and tenderness on percussion was present on both teeth. Radiographic investigation ascertained pulpal involvement and periodontal ligament widening in both teeth, leading to the diagnosis of "symptomatic irreversible pulpitis with apical periodontitis." Endodontic treatment was considered for these teeth. The preoperative radiograph of the premolars revealed bifurcated root and two canals $(-$ Fig. 1A). After anesthetizing the teeth and isolating with rubber dam, endodontic access cavity was prepared and enlarged. Magnifying loupe (Ergoptix, Pune, India) was used to observe pulp chambers and canal orifices were negotiated using sharp
DG 16 explorer (GDC, India). After obtaining the canal patency, a \#10K file (Mani, Utsunomiya, Japan) was precurved to traverse the canal bifurcation into the second root. After extirpation of the pulpal tissue, a working length determination radio-

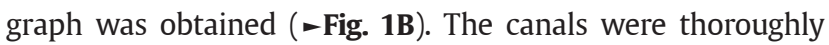
cleaned and shaped using NeoEndo Flex file system (Orikam Healthcare, India) up to 30 (4\% taper), along with continuous irrigation using $2.5 \%$ sodium hypochlorite solution (Prime Dental Products, India) and $17 \%$ ethylenediaminetetraacetic acid (EDTA) solution (Prime dental products, India). Finally, paper points were used to dry the prepared canals and obturation (Gutta Percha cones, Meta BioMed, South Korea) was done using lateral compaction method ( - Fig. 1C, D).

\section{Case Report 2}

A 35-year-old woman reported to the Department of Endodontics with a chief complaint of blackish discoloration in right back tooth region. Oral examination revealed caries with respect to mandibular canine and first premolar. Radiographic examination ascertained involvement of pulp and periapical radiolucency in relation to both teeth, leading to the diagnosis of "pulp necrosis and asymptomatic apical periodontitis." Endodontic treatment was considered for both teeth. The preoperative radiograph of the premolar also revealed bifurcated root and two canals ( $\neg$ Fig. 2A). The tooth was anesthetized, and after isolation access cavity preparation was done and pulp chamber was enlarged. Magnifying loupe (Ergoptix, India) was used to observe pulp chamber and canal orifice were negotiated using sharp DG 16 explorer.
DOI https://doi.org/

10.1055/s-0040-1709096

ISSN 2321-1482.
C2020 Bhojia Dental College and Hospital affiliated to Himachal Pradesh University
License terms

(우 (1) $\Theta \circledast$ 

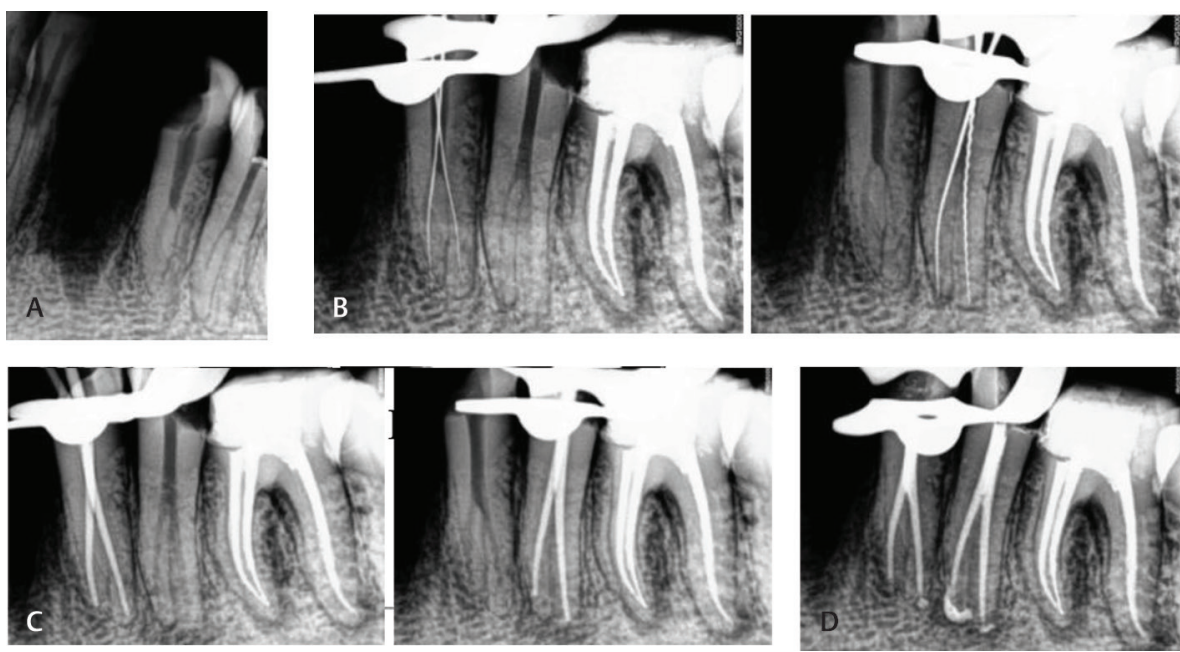

Fig. 1 (A) Diagnostic radiograph showing caries extending up to the pulp and widening of periodontal ligament with respect to mandibular left first and second premolar. Fast break of the canals in both teeth was suggestive of more than one canal in both the teeth. (B) Working length radiograph revealing bifurcated canals (Weine's type IV) (C) Master cone radiograph. (D) Obturation radiograph.
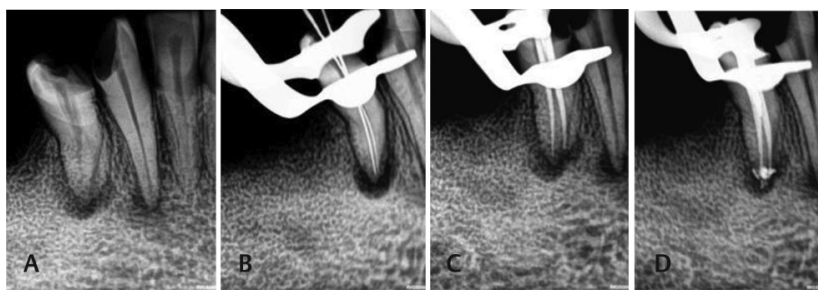

Fig. 2 (A) Diagnostic radiograph showing caries extending up to the pulp and periapical radiolucency with respect to mandibular right canine and first premolar. (B) Working length radiograph. (C) Master cone radiograph. (D) Obturation radiograph.

(GDC, India). After obtaining the canal patency, a \#10K file (Mani, Utsunomiya, Japan) was precurved to traverse the canal bifurcation into the second root. After extirpation of the pulpal tissue, a working length determination radiograph was obtained ( - Fig. 2B). The canals were cleaned and shaped using NeoEndo Flex file system (Orikam Healthcare, India) up to \#25 (6\% taper), along with continuous irrigation with $2.5 \%$ sodium hypochlorite solution (Prime Dental Products, India) and 17\% EDTA solution (Prime Dental Products, India). Finally paper points were used to dry the prepared canals and obturation (Gutta Percha Cones, Meta BioMed, South Korea) was done using lateral compaction method ( - Fig. 2C, D).

\section{Case Report 3}

A 38-year-old man reported to the Department of Endodontics complaining of food lodgment in left back tooth region. Oral examination revealed caries with respect to mandibular left first and second premolar. Radiographic examination revealed pulpal involvement in relation to both teeth, leading to diagnosis of "asymptomatic irreversible pulpitis." Endodontic treatment was considered for both teeth. The preoperative radiograph of the first premolar revealed bifurcated root and two canals ( - Fig. 3A). After anesthetizing, the offending teeth were isolated with rubber dam and endodontic access cavity were prepared. Magnifying loupe (Ergoptix, India) was used to observe pulp chamber and canal orifices were negotiated using sharp DG 16 explorer (GDC, India). After obtaining the canal patency, a \#10K file (Mani, Utsunomiya, Japan) was precurved to traverse the canal bifurcation into the second canal. After extirpation of the pulpal tissue, a working length determination radiograph was obtained ( - Fig. $3 B$ ). The canals were cleaned and shaped using NeoEndo Flex file system (Orikam Healthcare, India) up till \#25 (6\% taper), along with continuous irrigation with $2.5 \%$ sodium hypochlorite solution (Prime Dental Products, India) and 17\% EDTA solution (Prime Dental Products, India). Finally paper points were used to dry the prepared canals and obturation (Gutta Percha Cones,
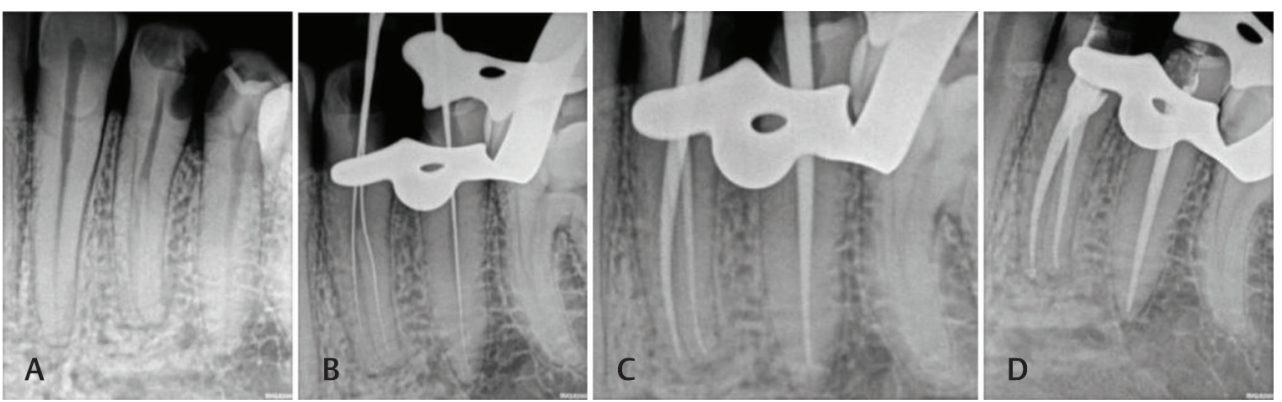

Fig. 3 (A) Diagnostic radiograph showing caries extending up to the pulp with respect to mandibular left first and second premolar. Fast break of the canal in first premolar was suggestive of more than one canal in the tooth. (B) Working length radiograph revealing bifurcated canal (Weine's type IV) in first premolar. (C). Master cone radiograph. (D) Obturation radiograph. 
Table 1 Data cited from different anatomical studies depicting number of canals and apices for mandibular first premolars ${ }^{8}$

\begin{tabular}{|l|l|l|l|l|l|l|}
\hline $\begin{array}{l}\text { Number of canals } \\
\text { and apices }\end{array}$ & $\begin{array}{l}\text { Number of } \\
\text { studies cited }\end{array}$ & $\begin{array}{l}\text { Number of teeth } \\
\text { (canals studies) }\end{array}$ & One canal & $\begin{array}{l}\text { Two or more } \\
\text { canals }\end{array}$ & $\begin{array}{l}\text { One canal at } \\
\text { apex }\end{array}$ & $\begin{array}{l}\text { Two or more } \\
\text { canals at apex }\end{array}$ \\
\hline- & 16 & 4,733 & $\begin{array}{l}75.8 \% \\
(3,586)\end{array}$ & $\begin{array}{l}24.2 \% \\
(1,147)\end{array}$ & - & - \\
\hline- & 10 & - & - & $\begin{array}{l}78.9 \% \\
(2,054)\end{array}$ & $\begin{array}{l}21.1 \% \\
(550)\end{array}$ \\
\hline
\end{tabular}

Meta BioMed, South Korea) was done using lateral compaction method (-Fig. 3C, D).

\section{Discussion}

The apical configuration of mandibular premolars is complex and the presence of additional roots or canals is an endodontic demur. Scott and Turner (2000) in their study depicted the presence of accessory root in mandibular first premolar and termed it as Tome's root. ${ }^{3}$ They are one of the most challenging teeth for root canal therapy, especially type IV (Weine's classification) as the main canal divides far below the orifice making it difficult to discover the accessory canals. England et al (1991) reported that if a radiolucent line is found mesial or distal to the main canal, the presence of a secondary canal should be asserted. Nearly all of the secondary canals originate on buccal or lingual walls and generally exit the main canal at an acute angle. ${ }^{4}$

In studies on anatomical and morphological configurations of mandibular first premolars it was reported that 23 to $30 \%$ are more prone to bifurcation of canals and 15 to $20 \%$ terminate in multiple apical foramina. ${ }^{5}$ Zillich and Dowson (1973) also proclaimed that "a second or third canal exists in at least $23 \%$ of first mandibular bicuspids" and the canals may divide anywhere along the path of main canal., ${ }^{6,7}$ Data cited from different anatomical studies that included only mandibular first premolars revealed that $21.1 \%$ cases showed two or more canals at the apex ${ }^{8}$ ( - Table $\mathbf{1}$ ).

Sert and Bayrili (2004) surveyed differences in canal morphology on the basis of gender, showing higher incidence (44\%) of accessory roots and canals in females as compared with males (34\%). ${ }^{9}$ Ethnicity also has a significant influence on aberrant anatomy. Two and three canal premolars are often seen in African-American populations. ${ }^{10}$ Thus, a variety of factors contribute to deviation in root anatomy of mandibular first premolars.

A series of preoperative radiographs and their careful interpretation may acquaint the clinician with the variation in root canal morphology. Changing the horizontal angle (straight, mesial, and distal angled) of the X-ray tube head facilitates the identification of overlapping canals; thus, one can identify the presence of extra canals in mandibular first premolars. ${ }^{11}$ These accessory canals can be best identified using a small, precurved \#10K file. ${ }^{4}$ To enhance visualization and locate canal orifices, magnification devices such as loupes or microscope could be used. Cone beam computed tomography can also be used as an adjunct in case of difficulty locating the extra canals. ${ }^{6}$ Midtreatment flare-ups and poor prognosis can occur as a result of failure to recognize the presence of additional root or canals. ${ }^{6}$ Thus, clinicians should keep themselves abreast with latest technologies and have complete understanding of the pulp space and its variations so as to manage them appropriately.

\section{Conclusion}

Successful outcome cannot be ensured but earnest efforts by the clinician should be made to minimize failure. Judicious use of all the available diagnostic aids is crucial for treatment planning. Meticulous knowledge of the anatomy and variations in the morphology, correct interpretation of radiograph, careful inspection of chamber floor, and modification of access opening if two or more canals are suspected are cardinals for a favorable outcome.

\section{Conflict of Interest}

None declared.

\section{References}

1 Hoen MM, Pink FE. Contemporary endodontic retreatments: an analysis based on clinical treatment findings. J Endod 2002;28(12):834-836

2 Slowey RR. Root canal anatomy. Road map to successful endodontics. Dent Clin North Am 1979;23(4):555-573

3 Scott R, Turner C. The Anthropology of Modern Human Teeth. Cambridge, UK: Cambridge University Press; 2000

4 England MC Jr, Hartwell GR, Lance JR. Detection and treatment of multiple canals in mandibular premolars. J Endod 1991;17(4):174-178

5 Kottoor J, Albuquerque D, Velmurugan N, Kuruvilla J. Root anatomy and root canal configuration of human permanent mandibular premolars: a systematic review. Anat Res Int 2013;2013:254250

6 Zillich R, Dowson J. Root canal morphology of mandibular first and second premolars. Oral Surg Oral Med Oral Pathol 1973;36(5):738-744

7 Vertucci FJ. Root canal morphology of mandibular premolars. J Am Dent Assoc 1978;97(1):47-50

8 Ingle J, Bakland L. Endodontics. 6th ed. Hamilton, ON: Becker; 2008

9 Sert S, Bayirli GS. Evaluation of the root canal configurations of the mandibular and maxillary permanent teeth by gender in the Turkish population. J Endod 2004;30(6):391-398

10 Trope M, Elfenbein L, Tronstad L. Mandibular premolars with more than one root canal in different race groups. J Endod 1986;12(8):343-345

11 Martínez-Lozano MA, Forner-Navarro L, Sánchez-Cortés JL. Analysis of radiologic factors in determining premolar root canal systems. Oral Surg Oral Med Oral Pathol Oral Radiol Endod 1999;88(6):719-722 